\title{
O Acesso das Mulheres Vítimas da Violência Doméstica à Justiça
}

\author{
Mariana Alvarenga Eghrari Pereira
}

Mestranda do curso de Direito e Políticas Públicas da Uniceub com a pesquisa na área de violência doméstica, a partir das perspectivas de gênero no Judiciário. Possui experiência como coordenadora de projetos no campo dos direitos humanos por meio da efetivação de políticas públicas, tendo como um de seus principais trabalhos a coordenação do Seminário Protegendo as Mulheres da Violência Doméstica. marianaeghrari@hotmail.com

\section{Resumo:}

Discute-se neste trabalho se há acesso à Justiça às mulheres vítimas de violência doméstica. A discussão vai muito além do acesso formal à Justiça; vai em busca de uma ordem jurídica justa que atue como um mecanismo de empoderamento a essas mulheres. 0 texto apresenta uma breve análise histórica da figura das mulheres no espaço jurídico e seus reflexos na atualidade jurídica e social, e como a política de proteção à mulher vítima de violência doméstica, no âmbito do judiciário, precisa ser mais bem avaliada.

Palavras-chave: Acesso à Justiça. Violência doméstica. Política pública.

\section{JUDICIAL ACCESS FOR WOMEN'S VICTIMS OF DOMESTIC VIOLENCE}

\begin{abstract}
:
This work analyses if the victims of domestic violence have accesses to the judicial system. The discussion goes beyond the formal access to justice, but in the pursuit of a just legal system that acts as a mechanism to empower these women. The text presents a brief historical analysis of the figure of women in the legal space and its effects on the legal and social actuality and why the public policy to protect women victims of domestic violence within the judiciary needs to be better discussed.
\end{abstract}

Keywords: Access to Justice. Domestic Violence. Public Policies.

\section{Sumário:}

1 Introdução. 2 Acesso à Justiça e à História. 3 As mulheres e os novos direitos: um breve histórico. 4 As mudanças legislativas e culturais no acesso a uma ordem jurídica justa. 5 Conclusões. 6 Referências. 


\section{INTRODUÇÃO}

O presente trabalho reúne reflexões geradas a partir do estudo da política pública de combate à violência doméstica. A principal linha de análise foi a de compreender se há ou não, no espaço jurídico, acesso à Justiça às mulheres vítimas da violência doméstica, não apenas no aspecto formal deste conceito, mas possibilitando que este se torne um modo de garantir a efetividade de direitos dessas mulheres.

Uma breve análise histórica da inserção da mulher no espaço jurídico é apresentada, dando-se destaque aos avanços que tivemos nos últimos anos, em especial com o estabelecimento da atual política de combate à violência doméstica. Este trabalho demonstra, contudo, que é preciso que esta política seja constantemente avaliada para que a violência doméstica não seja combatida apenas mediante mecanismos judiciais, mas, sim, por meio de um conjunto de atores governamentais que possa, de fato, contribuir no empoderamento das mulheres vítimas da violência doméstica.

O trabalho apresenta algumas das observações e análises por mim realizadas durante a pesquisa de campo, consolidando dados para a minha Dissertação de Mestrado. A pesquisa foi realizada em campo entre os meses de outubro de 2012 e janeiro de 2013 nos Juizados de Violência Doméstica e Familiar Contra Mulher do Tribunal de Justiça do Distrito Federal e Territórios. Foram realizadas entrevistas com os juízes titulares desses Juizados e observações feitas a partir das audiências.

\section{ACESSO À JUSTIÇA E À HISTÓRIA}

Ao se falar de acesso à Justiça, esse pode ser analisado por meio de dois prismas. O primeiro, ${ }^{1}$ pautado na solução de litígios que adotava uma filosofia individualista dos direitos, no qual ter acesso à proteção judicial

${ }^{1}$ Conceito adotado pelos Estados Liberais Burgueses nos séculos 18 e 19. 
significava essencialmente o direito formal do indivíduo em propor ou contestar uma ação. Já o segundo prisma ${ }^{2}$ compreende o acesso à Justiça como a necessidade e o compromisso de se dar a todo indivíduo garantia e proteção dos seus direitos sociais e individuais na esfera judicial.

A primeira vertente entendia que o acesso à Justiça era um direito natural e, por isso, não necessitava de uma ação do Estado para a sua proteção. $\mathrm{O}$ direito era anterior ao Estado e cabia a esse apenas preservá-lo de modo que não fosse infringido por outros. Dessa forma, a Justiça somente era possível àqueles que tivessem recursos financeiros para enfrentar os seus custos e, assim, ela acabava por incapacitar principalmente os pobres de ter acesso à Justiça. A ausência de igualdade entre os litigantes não era vista como um problema. A preocupação principal do sistema Judiciário era meramente formal quanto ao julgamento das normas e seus procedimentos.

Nesse primeiro momento, a realidade social não era uma preocupação dos estudiosos do Direito. À medida que a sociedade começa a se tornar cada vez mais complexa em suas relações, surgem conceitos que mudam essa perspectiva individualista do sistema Judiciário, que passa a ver a garantia dos direitos, principalmente, a partir dos conceitos de direitos humanos, como algo de caráter coletivo. Passa-se a reconhecer, então, os direitos e deveres sociais dos governos, comunidades, associações e indivíduos.

A garantia de "novos" direitos surge com a constituição francesa de 1946, que garante direitos ao trabalho, à saúde, à segurança material e à educação. O Estado passa do seu polo passivo, quanto a sua atuação, para então assegurar o gozo de todos os direitos sociais básicos. $\mathrm{O}$ acesso à Justiça ganha importância na medida em que é preciso que todo o indivíduo

${ }^{2}$ Conceito adotado no século 20 no pós-guerra e, principalmente, com a promulgação da Declaração Universal dos Direitos Humanos. 
tenha garantia e proteção a esses novos direitos sociais e individuais. Para se reivindicar direitos é preciso que o Estado disponibilize mecanismos que garantam a sua efetividade. $\mathrm{O}$ acesso à Justiça torna-se um direito cuja denegação acarretaria a negação de todos os demais direitos.

A partir do momento em que o acesso à Justiça se torna um modo de garantir a efetividade de direitos, é preciso repensar as técnicas processuais de forma a solucionar conflitos e criar alternativas ao sistema judicial formal. $\mathrm{O}$ direito processual passa a ter o desafio de se adaptar às novas funções sociais e aos direitos individuais delas decorrentes. Esse é, sem dúvida, um dos desafios do direito no final do século 20 e início do século 21.

É preciso ter-se em mente, dessa forma, que o acesso à Justiça é um instrumento de atuação da e para a Justiça, e o processo judicial não é o único meio de alcançá-lo. As leis de nada adiantam se elas não puderem alcançar efetivamente o seio da comunidade, e isso de forma justa. Não podemos pensar "com supina ingenuidade que, frente a um problema, é preciso editar uma lei. Isto não faz mais do que depreciar o poder normativo” (Bezerra, 2001, p. 94).

Ou seja, o Judiciário e o poder Legislativo, no atual momento, precisam adaptar-se, mais do que nunca, às atuais demandas sociais para que não sejamos um país de leis que não dispõem, acima de tudo, de uma efetividade social.

\section{AS MULHERES E OS NOVOS DIREITOS: UM BREVE HISTÓRICO}

A transição entre o século 20 e o 21 é marcada pelo cenário em que novos direitos e novas formas de se pensar e aplicar o direito precisam ser trabalhadas. Os direitos das mulheres passam, assim, a ser discutidos no âmbito social e jurídico e, ao falarmos desses direitos, toda uma cultura 
jurídica começa a ser tensionada a refletir sobre os direitos de um grupo social que até então era invisível, principalmente no campo jurídico. Isso pelo fato de o nosso sistema legislativo não ter garantido, durante séculos, a possibilidade às mulheres de serem tratadas como "sujeitos" de direitos no sistema judicial.

O sistema judicial inicialmente fora pensado para tratar de questões de apenas uma esfera da sociedade - a masculina. Ao analisarmos brevemente as questões de gênero nas relações familiares e conjugais, é possível observar que a própria legislação dava amparo à manutenção da desigualdade entre homens e mulheres. Observa-se, por exemplo, nas Ordenações Filipinas, ${ }^{3}$ que se encontravam vigentes no Brasil até início do século 20, que o homem casado tinha garantido todo e qualquer direito sob a sua mulher, inclusive o direito de castigá-la e matá-la em caso de adultério: Livro 5 - Título XXXVIII - Achando o homem casado sua mulher em adultério, licitamente poderá matar assi a ela, como o adultero, salvo se o marido for peão e o adultero fidalgo... (Machado, 2006).

Ainda no início do século 20, o Código Civil de 1916 que até pouco tempo encontrava-se vigente, ilustra a continuidade do pensamento jurídico com relação aos direitos de homens e mulheres. As questões familiares permaneciam ali amparadas pela hierarquia familiar, na qual o marido tinha plenos direitos e a sua mulher se encontrava em uma situação de inferioridade legal, sendo considerada incapaz para certos atos jurídicos enquanto se encontrasse casada.

${ }^{3}$ As Ordenações Filipinas "eram compostos, cada um deles (sic), por um conjunto detalhado de normas que buscavam definir não apenas as relações dos indivíduos para com a Coroa portuguesa, como também normatizavam as relações privadas. Nesse sentido, regulavam comportamentos e atribuíam punições para as transgressões relativas à vida moral, à convivência doméstica e às relações conjugais" (Sousa; Brito; Barp, 2009, p. 65). 
O código trazia especificamente um capítulo sobre os direitos e deveres do marido e da mulher, no qual cabia a ele o direito de autorizar a profissão de sua mulher. ${ }^{4}$ As mulheres também eram proibidas de litigar em juízo civil ou comercial sem a autorização do marido. Ou seja, o acesso das mulheres à Justiça era impossibilitado por lei, sendo permitido apenas em casos específicos. Somente em 1962, com o Estatuto da Mulher Casada, que as mulheres passam a ter alguns ganhos relacionados às questões civis, passando a ter maiores garantias e direitos enquanto sujeitos de direitos.

Os vários séculos em que as mulheres foram impedidas legalmente de ter acesso à Justiça e, consequentemente, a sua invisibilidade junto ao judiciário, geraram reflexos nos dias de hoje, principalmente ao tratarmos de questões de cunho íntimo e familiar, como a violência doméstica contra as mulheres. Criou-se uma barreira cultural e social ao acesso à Justiça às mulheres, uma vez que estas não eram vistas legalmente como parte desse sistema.

A não participação feminina no mundo legal também gerou consequências e reflexos na sua presença na magistratura e outras funções do Judiciário. Na década de 60 as mulheres juízas tinham uma representação de 2,3\% nesse campo, estatística que atingiu 30\% no ano de $2012 .{ }^{5}$ Mesmo com esse grande aumento na participação das mulheres na magistratura, a maior parte da população feminina ainda se vê pouco representada nessa importante esfera pública. Em muitos casos essa não representação dificulta ainda mais o acesso de mulheres à Justiça, uma vez que não se veem como parte daquele espaço e, por isso, temem ou desacreditam que os seus conflitos íntimos e familiares podem ali ser resolvidos.

\footnotetext{
${ }^{4}$ Artigo 233, Inciso IV: O direito de autorizar a profissão da mulher e sua residência fora do teto conjugal.

${ }^{5}$ Fonte: <http://www.observatoriodegenero.gov.br/menu/noticias/participacao-das-mulheres-no-judiciario-aumentou/>. Acesso em: 5 fev. 2013.
} 
Para que o acesso à Justiça seja garantido plenamente, é preciso que se tenha igualdade de oportunidades no acesso às instituições, aos órgãos de poder do Estado que a produzem, aplicam e interpretam as leis e regulam normas que impactam no bem-estar social e econômico. Além disso, ter acesso à Justiça é garantir que se viabilize um acesso à ordem jurídica justa, e é justamente esse o ponto que queremos discutir. As mulheres, vítimas de violência doméstica, têm acesso à Justiça e a uma ordem jurídica justa?

Para que essa pergunta comece a ser respondida é preciso que se questione até que ponto o acesso à Justiça, nos casos de violência doméstica, é possível enquanto a maior parte das mulheres ainda desacredita na Justiça nesses casos. Uma pesquisa ${ }^{6}$ aponta que a maioria das pessoas não acredita na proteção jurídica e policial e 56\% dos entrevistados são céticos com relação a essas proteções. A pesquisa concluiu que mesmo “[...] acreditando que hoje a mulher está mais protegida legalmente, a maioria dos entrevistados não confia nas pessoas que estão à frente do aparato do Estado, justamente aquelas responsáveis por fazer cumprir a lei e consequentemente proteger a mulher agredida” (Instituto Avon/ Ibope, 2009, p. 16).

No ano de 2011 nova pesquisa foi realizada e 59\% das mulheres desacreditam na Justiça e em sua proteção. Para 52\% dos entrevistados, essa descrença se deve à desqualificação do problema por parte dos juízes e policiais.

Essa desqualificação pode ser apontada como uma das razões que impedem o acesso de mulheres vítimas de violência doméstica à Justiça. Isso porque os operadores do direito ainda não se encontram sensibilizados e capacitados para atender essas mulheres e esse processo de mudança cultural no campo do direito, que é social, gradual e lento.

${ }^{6}$ Instituto Avon/Ibope. Percepções sobre a violência doméstica contra a mulher no Brasil. 2009 . 
Ainda hoje pode-se observar em salas de audiência comentários de operadores do direito que claramente diminuem a violência doméstica e retiram dos agressores a "culpa” pelos atos praticados. Durante as audiências que compareci, para minha pesquisa de Mestrado, pude ouvir de um policial civil, testemunha em um processo de violência doméstica, que ainda na delegacia disse à ofendida que: "Olha, a senhora tem filhos com ele”. E perguntou "se ela queria levar o procedimento adiante”. Ela afirmou que sim, porque já havia sido agredida anteriormente.

Percebe-se que, antes mesmo de registrar a ocorrência, o policial civil já desencoraja o ato por parte da ofendida e deixa isso claro em audiência, como se ele estivesse fazendo um favor às partes, posto que, para ele, aquele caso não era de muita relevância. Durante a audiência o agente policial também já emite o seu juízo de valor quanto ao ofensor: "Ele não deve ser uma pessoa tão má assim, já que o filho de 2 anos não queria que o pai fosse preso e se agarrava a sua perna pedindo que não levasse o seu pai”.

$\mathrm{Na}$ década de 80 mudanças essenciais começaram a ser tomadas de forma a se tratar o problema da violência doméstica como uma questão pública e não mais privada. Uma agenda social mais efetiva começa a ser pensada nesse período, sendo uma de suas ações, após forte influência do movimento de mulheres, a criação das Delegacias de Mulheres - Deams que surgiram pela necessidade de se dar atenção e voz, no espaço público, às mulheres no trato de questões de violência.

As delegacias, contudo, não conseguiram se tornar imediatamente uma porta de acesso das mulheres à Justiça. Isso porque elas eram desencorajadas já nas delegacias a darem prosseguimento as suas denúncias, uma vez que os policiais que as atendiam as intimidavam em um primeiro momento, ao dizerem que se fizessem a denúncia não poderiam voltar 
atrás, indagando se tinham certeza que gostariam de denunciar seus maridos. Ou seja, uma série de perguntas e colocações era apontada que amedrontava as mulheres a dar seguimento as suas denúncias.

Com a vigência da Lei 9.099/95 essa primeira barreira de acesso à Justiça, identificada nas delegacias, foi, de certa forma, desobstruída com a necessidade de se remeter ao Judiciário o Termo Circunstanciado (TC) com o relato do crime ocorrido. ${ }^{7}$ Com isso, os crimes de violência doméstica contra a mulher passaram a ingressar nos relatórios formais das secretarias de segurança pública, dando visibilidade a esta questão e apontando ao poder público que algo precisava ser feito.

Ao serem encaminhados aos juizados especiais, os Termos Circunstanciados davam início a um possível processo judicial, garantindo em parte o acesso formal à Justiça de mulheres vítimas da violência doméstica. Antes do início do processo, as partes eram convocadas a participar de uma audiência de conciliação, quando se buscava um diálogo entre a vítima e o agressor para a resolução do conflito. Caso não chegassem a um acordo, o processo era então encaminhado ao juiz que as ouviria, já em fase processual, e faria o julgamento da ação. Nos casos de condenação do agressor, esse era obrigado ao pagamento de cestas básicas ou à prestação de serviços à comunidade por período estipulado.

Esse abrandamento nas condenações dos agressores e a ausência de penas mais severas, também era um fator que afastava as mulheres na busca pela Justiça. A lei dos juizados especiais não conseguiu diminuir os casos de violência doméstica por uma série de razões que podemos elencar a partir de informações analisadas: a) para as vítimas a lei era ineficaz, uma vez que não resolvia os seus problemas com a violência doméstica, mantendo-as no ciclo da violência; b) elas também se sentiam amedrontadas ao terem de discutir, frente a frente com seus agressores,

${ }^{7}$ No Termo Circunstanciado não há a oitiva de testemunhas e nem do agressor, prática que ocorre no Inquérito Policial. Tem-se apenas a versão da vítima quanto aos fatos ocorridos. 
os seus problemas "pessoais" diante de um terceiro desconhecido e que muitas vezes não lhes dava a atenção e orientação que precisavam naquele momento de fragilidade. Muitas permaneciam caladas ou desistiam da ação processual já na fase de conciliação por medo de sofrem mais violência ao retornarem junto com os seus agressores para casa. Muitas vezes o próprio conciliador, promotor ou juiz, induzia as vítimas a desistirem na continuidade da ação penal. Em muitos casos relatados as mulheres eram ridicularizadas pelos juízes e promotores (sem distinção aqui de sexo), que acreditavam que estas sofriam violência por que queriam, uma vez que, para eles, elas poderiam cessar o ciclo da violência a qualquer momento.

Observa-se que havia, por parte do Judiciário, um completo despreparo no atendimento às mulheres vítimas de violência doméstica e, por outro lado, quando da condenação dos agressores, a "pena” a eles imputada era vista somente como uma despesa econômica, posto que, na maioria dos casos, lhes era estipulado o pagamento de algumas cestas básicas. Muitos juízes, em razão da dúvida da vítima em continuar com a ação penal ou nos casos de reincidência do réu, abrandavam a pena, uma vez que desconfiavam das reais intenções da vítima.

Não se pode negar, contudo, que a lei 9.999/95 trouxe pela primeira vez um alerta de que crimes de violência doméstica precisavam de uma intervenção estatal imediata e viabilizaram um maior acesso formal de mulheres vítimas de violência doméstica ao Judiciário. A lei, entretanto, ainda não era eficaz no que concerne ao empoderamento das mulheres, a quebra do ciclo da violência e o acesso a uma ordem jurídica justa.

\section{AS MUDANÇAS LEGISLATIVAS E CULTURAIS NO ACESSO A UMA ORDEM JURÍDICA JUSTA}

Os operadores do direito aos poucos foram compreendendo a necessidade de se aplicar o direito de forma harmônica e adequada às necessidades sociais. Observa-se, contudo, que a ausência de uma legisla- 
ção específica de enfrentamento à violência ainda impedia que as mulheres tivessem um processo legal que pudesse, de fato, protegê-las, atendendo as suas necessidades imediatas e específicas, de forma a cessar a violência e que possibilitasse que as punições aos agressores pudessem realmente conduzi-los a repensar o porquê da prática da violência.

Com a criação da Secretaria Especial de Políticas para as Mulheres em 2003, começa a se propor uma política específica de enfrentamento à violência doméstica e familiar contra a mulher, de forma a garantir a elas um atendimento integral, humanizado e de qualidade. Algo que até então não vinha ocorrendo. Para que isso fosse possível, era preciso instituir e garantir o funcionamento das redes de atendimento à mulher em situação de violência e principalmente capacitar e treinar os profissionais que atendiam essas mulheres.

Essa política ganhou maior visibilidade após a entrada em vigor da lei 11.340/06, conhecida popularmente como Lei Maria da Penha que contou, ao longo do seu processo de proposição e efetivação, com a participação direta do movimento de mulheres em articulação com os poderes Executivo e Legislativo em âmbito federal.

Um dos principais pontos da proposição era a promoção de assistência à mulher em situação de violência doméstica, com medidas integradas de prevenção por meio de ações conjugadas de diferentes atores governamentais e não governamentais, formando, assim, uma rede de atendimento à mulher em situação de violência. Além disso, previa a criação de varas especializadas, no Judiciário, para atendimento aos casos de violência doméstica.

A observância da nova lei no mundo jurídico, a partir de setembro de 2006, trouxe consigo uma série de discussões e desafios, mas o maior deles é o de mudar toda uma cultura, valores e mentalidade jurídica/ social e garantir a defesa da mulher enquanto indivíduo, sujeito e não mais enquanto "membro" de uma família. 
Outro ponto que a lei traz é a importância de se tratar a violência doméstica como uma política pública envolvendo diferentes atores no seu combate. Para que a atual política possa, de fato, empoderar e ajudar essas vítimas, no entanto, é preciso que ela seja vista como "um conjunto dotado de sentido”, em que cada um dos atores dessa rede de proteção à mulher têm um papel fundamental no seu empoderamento e cada uma das suas ações precisa ser realizada de forma coordenada para uma maior eficácia da política.

Após a entrada em vigor da Lei 11.340/06, observa-se, de acordo $\operatorname{com}_{\text {dados }}^{8}$ do Conselho Nacional de Justiça - CNJ - de setembro de 2006 a dezembro de 2011, que 685.905 procedimentos foram instaurados para coibir os crimes de violência doméstica. Em junho de 2010 as varas e juizados especializados de violência doméstica julgaram 110.998 processos, e em dezembro de 2011 esse número tinha subido para 408.013 processos.

Os dados mais do que demonstram um real e surpreendente aumento no número de processos em todo o país e, muitas vezes, questionou-se se realmente o número de crimes de violência doméstica estava aumentando no país ou se agora esses passavam a ser mais denunciados pelas mulheres. Ficamos com a segunda opção. As mulheres, com a Lei Maria da Penha, se "empoderaram juridicamente" na busca por seus direitos. De acordo com Boaventura de Sousa Santos, "as pessoas, tendo consciência dos seus direitos, ao verem colocadas em causa às políticas sociais ou de desenvolvimento do Estado, recorrem aos tribunais para as protegerem ou exigirem a sua efetiva execução” ${ }^{9}$

${ }^{8}$ Informações retiradas do site do CNJ. Disponível em: <http://www.cnj.jus.br/noticias/ cnj/20607-lei-maria-da-penha-completa-seis-anos-de-vigencia>. Acesso em 19 fev. 2013.

${ }^{9}$ SANTOS, Boaventura de Sousa. Para uma revolução democrática da Justiça. 2011. P,15 Disponível em: <http://72.29.69.19/ ejal/images/stories/arquivos/RevDemJust_FEV2011.pdfs. 
A Lei Maria da Penha trouxe, como uma das suas principais ferramentas, a difusão de conceitos jurídicos e de direitos junto a população. A informação sobre a Lei 11.340/06 já chega a quase $98 \%$ das entrevistadas de pesquisa realizada pelo Datasenado. ${ }^{10}$ Nessa mesma pesquisa, as mulheres ainda afirmam que conhecer a lei não faz com que denunciem o fato às autoridades. Isso porque ainda temem a exposição dos agressores, e também não poder mais retirar a queixa-crime na delegacia faz com que deixem de denunciar as agressões.

Ou seja, as mulheres se veem impedidas de acessar à Justiça pelo temor de represálias e mais agressões por parte de seus companheiros e maridos caso venham a recorrer ao Judiciário. $\mathrm{O}$ fato de não poderem retirar a queixa ainda na fase policial, as deixa mais inseguras. É por isso que, muitas vezes, as mulheres, já no início da fase judicial, nas audiências preliminares, pedem o arquivamento dos processos por temer seus agressores ou, muitas vezes, por não querer prejudicá-los. Isso porque as condenações penais geram uma ficha "suja” temporal que os impede, então, de arrumar um emprego ou por serem tachados como criminosos pela sociedade.

Esses medos de realizarem as suas denúncias também têm reflexos diretos na fase judicial. Ainda se observa um desencorajamento por parte dos magistrados, principalmente, e do Ministério Público, em segundo plano, no prosseguimento dos crimes de violência doméstica. Pude observar durante audiências em Juizados Especiais de Violência Doméstica e Familiar contra a Mulher no Distrito Federal, a forma como os magistra-

${ }^{10}$ Pesquisa Datasenado. Violência Doméstica e familiar contra a mulher: pesquisa de opinião pública nacional. 2011. 
dos ainda minimizam esses crimes pelo fato de a vítima ter retornado ao convívio familiar com o agressor. Nas audiências preliminares ao prosseguimento da ação isso fica muito claro na fala de alguns magistrados. ${ }^{11}$

Em uma dessas audiências, ${ }^{12}$ a juíza, por exemplo, ao iniciar a audiência, pergunta à vítima e ao ofensor se os dois ainda estavam juntos. Para tanto, uma série de perguntas foram feitas pela juíza que questionava por diversas vezes se o casal já tinha retornado ao convívio marital e familiar. O tom da juíza ao perguntar o "Já voltaram?”, parece com um tom de deboche, mais ou menos passando a impressão de que ela está cansada de ver esses casos de violência em que as partes se desentendem e, em seguida, retornam ao convívio.

Esse contínuo romper e reatar a relação é muito comum nos casos de violência doméstica contra a mulher. $\mathrm{O}$ ciclo da violência perdura muitas vezes por anos e anos. Os agressores agridem física e verbalmente as vítimas que se submetem a essas agressões por uma série de questões culturais, emocionais e religiosas, que, nesse momento, não iremos explorar. Após as agressões, na maioria dos casos os agressores se arrependem do que fizeram e voltam a ter uma relação temporariamente harmoniosa com as vítimas.

Compreender esse ciclo da violência é fundamental ao se julgar crimes de violência doméstica. Em muitos casos, durante a audiência, as vítimas se culpam pela violência ocorrida, dizendo que provocaram o agressor, que o agrediram primeiro. Baseando-se nessa fala, pude observar, em alguns casos, que os magistrados se valem dela para propor à vítima o arquivamento do processo. Essa observação pode representar

\footnotetext{
${ }^{11} \mathrm{O}$ nome dos magistrados e os Juizados Especiais de Violências Doméstica e Familiar dos quais são titulares, também não será citado neste trabalho para preservar os seus posicionamentos.

${ }^{12}$ Audiências ocorridas entre outubro de 2012 e janeiro de 2013 em Juizados Especiais de Violência Doméstica e Familiar do Distrito Federal.
} 
milhares de outros que ocorrem cotidianamente nos diversos juizados especiais de violência doméstica e familiar contra a mulher, ilustrando como o acesso à Justiça pode ser negado às mulheres vítimas de violência doméstica pelos próprios representantes do Estado.

A falta de sensibilização com o tema e o histórico cultural e social desses magistrados e promotores atua, muitas vezes, como um forte empecilho para que mulheres, principalmente as de baixa classe social, tenham o direito de prosseguir com os seus processos criminais.

Nem somente a falta de sensibilização, no entanto, é um obstáculo para cessar a violência doméstica na vida de milhares de mulheres. A política pública ainda não conseguiu acionar toda uma rede de apoio, fora do Judiciário, que possa acompanhar as mulheres e fortalecê-las em suas relações ou no rompimento definitivo destas.

Pude acompanhar uma audiência em que a ofendida tinha três processos ocorrendo naquela Vara, fora aqueles que haviam sido arquivados. Logo no início da audiência a juíza se recorda da ofendida e lhe diz:

Não sei mais o que o Estado pode fazer pela senhora. Todos os mecanismos estatais já foram esgotados. Não sei mais o que fazer. Na casa abrigo a senhora refletiu sobre a sua vida? Todas as medidas judiciais e policiais foram tomadas e a senhora sempre retorna. A senhora precisa romper com isso. Justiça nenhuma funciona se a pessoa não tiver iniciativa.

A frase final da juíza denuncia que é preciso, além do processo judicial, outros mecanismos que possam ajudar as mulheres vítimas de violência doméstica a se empoderarem. Estes, contudo, ainda são muito limitados e, às vezes, escassos em diversas cidades brasileiras. A Lei Maria da Penha deu um foco muito grande à questão processual e criminal desses atos de violências, mas o Judiciário, por si só, é incapaz de solucionar os problemas que geram a violência. 
Outro problema que se verifica no acesso à Justiça nos casos de violência doméstica é que esse não se restringe às típicas formas de denegação de acesso ao Judiciário que normalmente estão focadas na falta de recursos financeiros, conhecimento e informação para acessar à Justiça. Nos casos de violência doméstica, mulheres de classes altas que compõem a elite social também têm o seu direito de acesso à Justiça negado uma vez que pertencem a uma faixa social em que esses crimes são caracterizados como vergonhosos.

Essas mulheres não vão até o Judiciário pela vergonha de denunciarem os seus agressores e, assim, "sujarem” o nome de suas famílias e as suas aparências e relações familiares diante do espaço social em que se encontram incluídas. Para elas, a Justiça é negada não porque há uma barreira financeira, mas, sim, por uma barreira social/moral que as impede de atingir esse espaço.

Pesquisa ${ }^{13}$ realizada com foco na violência doméstica nas classes média e média alta realizou entrevistas com mulheres vítimas da violência nessa esfera social. Uma das entrevistadas diz que "O seu sogro pediu que ela não fizesse (a denúncia) e tentasse resolver o problema em casa” (Silva, 2007, p. 82). Mais adiante ela afirma que não quer processar o seu ex-marido criminalmente porque isso "[...] pode ser um histórico ruim para a minha filha e, por isso, não pretendo processá-lo” (Silva, 2007, p. 83).

A pesquisa mostra que as mulheres de classe média alta não pretendem dar continuidade a um processo criminal contra os seus agressores por um medo de "mancharem" socialmente a ficha criminal de seus ex-companheiros e, consequentemente, gerarem um desconforto social

\footnotetext{
${ }^{13}$ Silva, Bárbara Garcia Ribeiro Soares da. A violência conjugal contra mulheres da classe média do município de São Paulo. 2007. Dissertação (Mestrado) - Universidade de São Paulo, Programa de Pós-Graduação em Sociologia, São Paulo, 2007.
} 
perante os seus filhos. Há, ainda, nas classes sociais mais altas, um temor pela chamada "ficha suja" e suas consequências em diversas áreas sociais, como no trabalho e na própria família. Por isso, essas mulheres preferem não acessar a Justiça para não gerar um desconforto social para os seus agressores e para a sua família.

Essas mulheres de classe média alta, entretanto, buscam o Judiciário e a polícia para que possam ter provas caso precisem lutar pela guarda de seus filhos. A pesquisa mostra que elas fazem a denúncia de agressão física ou psicológica de seus ex-maridos por medo de perderem a guarda de seus filhos. “[...] afirmou (a vítima) ter realizado a denúncia, para ter um documento que comprove a atitude violenta do seu ex-marido, caso necessite, futuramente, num processo judicial pela guarda das crianças" (Silva, 2007, p. 85).

Diante desse quadro, uma breve reflexão precisa ser feita. Será que os conflitos de violência doméstica de fato precisam ser conduzidos pela via judicial, ou alternativas para a sua solução podem ser utilizadas fora de um processo judicial?

Durante minha pesquisa, entrevistei a titular de uma vara de Violência Doméstica e Familiar do Distrito Federal. Essa afirmou que a via judicial ainda é importante para diminuir esse tipo de violência, porque o Estado, por meio da sua força, impõe às partes, e principalmente ao agressor, que aquela violência é séria, que ela precisa ser vista como uma coisa séria. $\mathrm{O}$ papel do Estado, nesses casos, é de justamente punir, uma vez que a violência doméstica, para essa juíza, é o berço da violência social. Por isso, o Estado deve intervir no seio dessas famílias vítimas de violência para mostrar a todos que a violência é passível de punição.

Para a juíza, a utilização de recursos da psicologia pelo Judiciário não funcionam nos casos de violência doméstica. A sala de audiência "não é um lugar para terapia”. Mesmo que a Lei 11.340/06 possibilite o encaminhamento da vítima e do agressor a um núcleo psicossocial, ela acredita 
que isso não seja adequado, uma vez que quem agride faz porque pode, porque as relações familiares patriarcalistas e machistas lhes dão esse poder. Por isso, ela acredita que a Justiça seja uma forma de mostrar ao agressor que a lei, o Judiciário, detém mais poder do que ele. "A Justiça é uma forma de dizer para o homem que ele não tem poder.”

Já outra juíza com quem conversei apontou em sua fala posicionamento diferente com relação ao papel do Judiciário nos casos de violência doméstica. Para ela, a Justiça tem de ir além da simples aplicação da pena, uma vez que "realizar a Justiça” é algo relativo, posto que a pura aplicação da lei não garante a efetividade de se realizar a Justiça, principalmente nos casos de violência doméstica contra a mulher. Para a magistrada, a Justiça e o acesso a ela devem ser vistos como um conjunto de fatores em que o empoderamento da vítima é uma das formas de se alcançar a Justiça, e o Estado deve ser visto como a última instância para se buscar a solução do conflito.

$\mathrm{Na}$ sua fala, a juíza afirma que, quando as mulheres vítimas de violência doméstica chegam ao Judiciário, elas buscam uma solução para as agressões que sofrem e não um processo judicial para tal. Não cabe ao Estado determinar a permanência ou não de uma relação familiar.

Se você (vítima) vai perdoar o seu marido, ou amante, o seu namorado por ele ter te agredido por mais que (isso) seja inconcebível. [...] Às vezes a pessoa não quer a separação. Ela só não quer mais apanhar. Talvez com um processo de ajuda, de fortalecimento (ajude mais que um processo). Você diz para um: "olha você não pode apanhar, você não tem que apanhar”. E você diz para o outro: "você não pode bater”, seja efetivo. E o que funciona para um não funciona para o outro. É muito complexo.

Os posicionamentos da primeira juíza, que acredita que o Estado deve apenas punir o agressor, uma vez que esse é o papel dado ao Judiciário, e o segundo posicionamento, que mostra que apenas a punição 
não irá melhorar a situação de violência doméstica, demonstram que a política pública ainda precisa ser mais bem analisada. Isso porque, antes de tudo, a política deve ter como enfoque principal o fim da violência doméstica e familiar no seio daquela família e, para isso, precisa incluir ações que tenham por foco tanto as mulheres agredidas quanto os seus agressores. $\mathrm{O}$ empoderamento das mulheres é mais do que necessário, mas realizar um trabalho com os agressores para que possam pensar e repensar o porquê de suas atitudes e das agressões, é essencial também. É preciso que todo o núcleo familiar, objeto da agressão, esteja presente neste "tratamento" de forma que se possa colaborar na mudança de toda uma dinâmica familiar marcada pela agressão.

\section{CONCLUSÕES}

Acredito que, se por um lado a coerção do Estado em demonstrar e aplicar a sua "força" pode surtir efeitos para o agressor, uma vez que a pena pode lhe gerar problemas futuros, como uma ficha criminal suja e inclusive a prisão, principalmente quando do descumprimento das medidas protetivas de proteção à mulher, por outro, ela pode afastar ainda mais a vítima na busca de ajuda no Judiciário pelo temor que ainda tem da máquina judicial e por não querer prejudicar o seu companheiro. $\mathrm{O}$ temor que as vítimas têm, muitas vezes, ocorre pelo desconhecimento sobre a forma de atuação do Judiciário, principalmente no que concerne aos procedimentos processuais e, em outros casos, pela forma como são acolhidas pelos operadores do direito, iniciando-se nas delegacias e terminando na presença dos magistrados.

Durante a minha pesquisa, verifiquei que em audiências as vítimas não recebem informações sobre os ritos processuais. Normalmente, os advogados que às atendem, gratuitamente, não conseguem explicar-lhes 
o que, de fato, irá ocorrer no processo e esclarecer quais são as consequências, ou não, que podem vir a ocorrer caso peçam o arquivamento do processo ou deixem de comparecer às audiências.

Outro problema é que as vítimas, em razão de um desconhecimento popular, acreditam que, caso condenados, seus companheiros irão diretamente para a prisão, e isso pode vir a implicar ausência de recursos financeiros para que possam manter a família durante a sua ausência. $\mathrm{O}$ que elas, de fato, não sabem, é que a maioria das penas, nos casos de condenação, não ultrapassam um ano e, nesses casos, o regime para cumprimento desta é o aberto. Ou seja, se essa informação fosse mais bem divulgada, talvez o temor quanto a uma condenação do agressor fosse menor.

O Judiciário ainda é um espaço desconhecido para muitas pessoas, o que ainda hoje cria barreiras para o acesso à Justiça e a uma ordem jurídica justa. É preciso que os mitos relacionados ao Judiciário e as barreiras da desinformação e do temor sejam quebradas para que o acesso à Justiça seja garantido. Atualmente, as barreiras econômicas quanto a esse acesso já foram derrubadas, mas ainda há, em especial nos crimes de violência doméstica contra a mulher, barreiras culturais e sociais que ainda as impedem de acessar à Justiça.

É preciso sim, neste momento, que o Estado trate dos crimes de violência doméstica e familiar contra a mulher condenando os agressores pelos atos de violência doméstica praticados, mas, por outro lado, é fundamental que um trabalho de reorganização das relações familiares e de empoderamento das mulheres seja realizado. Uma sentença não muda em nada, ou quase nada, a vida de uma pessoa que sofre ou pratica atos de violência doméstica, mas um bom acompanhamento psicossocial pode garantir à mulher a Justiça que ela tanto buscava.

A Lei Maria da Penha que, no seu texto legal traz uma série de compromissos governamentais, principalmente do Poder Executivo, não conseguiu até o momento instituir os mecanismos básicos e essenciais 
para o combate à violência doméstica. A Lei Maria da Penha, e talvez pelo fato de sua nomenclatura "lei”, acabou por “jogar” ao Judiciário todo o peso e dever no combate à violência doméstica.

Provavelmente o Judiciário não é o local para que as questões da violência doméstica sejam tratadas da maneira como estão sendo tratadas. Judicializar e criminalizar uma ato de violência pouco ou quase nada influencia na vida de milhares de agressores e das suas vítimas.

O Judiciário aplica a Lei Maria da Penha de acordo com o nosso código penal e de processo penal. A cultura estandardizada que domina a aplicação do direito penal permanece inalterada ao se julgar crimes de violência doméstica. $\mathrm{O}$ direito penal vale-se de fatos certos e determinados e, por isso, os julgamentos de crimes de violência doméstica se servem apenas dos fatos narrados e descritos para determinado crime ocorrido em horário e datas precisos.

Uma das juízas por mim entrevistada levanta um ponto importante de que o Estado transferiu ao Judiciário toda a carga sobre as questões de violência doméstica por meio da imposição de penas. Para ela, a Lei não pode se resumir ao campo jurídico/penal:

Tínhamos que ter escola em tempo integral para as mães deixarem os filhos. Você viu aqui uma (mulher) que disse "ah eu não posso fazer (acompanhamento psicossocial) porque eu não tenho com quem deixar os meninos”. Eu sempre escuto essa queixa. Creche para deixar essas crianças. Cadê isso? Nós precisamos capacitar a mulher [...] (Ter) programas de emancipação feminina. $E$ isso a gente não tem. Aí você tem um programa (de atendimento psicossocial) no setor comercial sul e ela mora lá no "cafifo", e não tem dinheiro para pagar a passagem. Você coloca uma lei dessa, bonita dessa, ela resumidamente só na imposição de pena? Implementação da ação por implementação de pena? 
Noto que os julgamentos dos crimes de violência doméstica não conseguem levar em consideração todo o histórico da violência, toda a problemática da violência doméstica que se caracteriza por comportamentos reiterados e cotidianos que carregam em si um alto grau de comprometimento emocional por parte da vítima, impedindo-a de romper a situação de violência e evitar, assim, que outros crimes venham a ocorrer simultaneamente.

Essa é uma das primeiras barreiras em que a Política de Combate à Violência Doméstica se esbarra a meu ver; isso porque o direito não consegue, dentro dos seus rígidos padrões normativos e dogmáticos, ser um instrumento de transformação na vida das mulheres vítimas da violência doméstica.

Ou seja, não cabe apenas ao Judiciário todo o trabalho de combater a violência doméstica e familiar contra a mulher. Ao Judiciário cabe punir ou não o agressor. $\mathrm{O}$ trabalho de empoderamento das mulheres e de suas famílias precisa ser realizado por outros órgãos estatais.

As mulheres não estão preocupadas com o seu acesso à Justiça, mas, sim, a uma ordem jurídica justa que possa atendê-las não pelo simples acesso formal à Justiça e as suas consequências legais. Dessa forma, apenas a judicialização da violência doméstica e familiar contra a mulher não é eficiente.

Ao entrevistar os magistrados, pude perceber que todos, unanimemente, destacam que as mulheres vítimas de violência doméstica, independente de sua classe social, quando recorrem ao Judiciário, o que esperam não é a punição de seus agressores, mas que a violência cesse e que as suas vidas possam mudar com isso. "Não é o processo crime. Não é a aplicação seca da lei. Elas querem que você (juiz) as ajude, buscam em você, o último recurso para ajudá-las a resolver aquela situação que elas não dão conta mais.” 
A pergunta se de fato a Lei Maria da Penha garantiu o acesso à Justiça às mulheres é difícil de ser respondida. Isso porque se pensarmos apenas nos aspectos formais do acesso à Justiça, a lei possibilitou, sim, o acesso à Justiça de uma parcela significativa das mulheres. Os dados do $\mathrm{CNJ}$ supra-apresentados, mais do que demonstram e comprovam que esse acesso formal à Justiça foi ampliado. Esses números, contudo, ainda poderiam ser muito maiores, uma vez que muitos operadores do Direito, em especial agentes policiais e magistrados, ainda menosprezam as denúncias trazidas pelas vítimas da violência doméstica, impossibilitando, conforme apresentado anteriormente, que estas deem continuidade às denúncias ou as façam.

Outro ponto é se, de fato, a Lei 11.340/06 é uma forma de Justiça e se ela garante a proteção de um direito das mulheres de não sofrerem mais com a violência doméstica. A aplicação da lei penal por meio de uma condenação não consegue atingir e minimizar de fato a violência doméstica. "Sujar" a folha penal do agressor nem sempre faz com que a violência cesse. As condenações podem atingir um número pequeno de agressores quanto aos prejuízos advindos de uma folha penal condenatória. Essa condenação, a meu ver, entretanto, não parece que faça com que uma maioria cesse a violência.

A aplicação penal não possui o viés de realizar um trabalho social, psicológico e educativo com os agressores e as vítimas da violência doméstica para que ambos se conscientizem quanto aos seus papéis na relação afetiva. A pena por si só não reeduca nesses casos. Ela pode até amedrontar o agressor e salvaguardar a vítima (por meio de medidas protetivas), mas ela não muda comportamentos.

Uma mudança, a meu ver, somente assim é possível: 1) trabalho integrado entre o Judiciário e órgãos estatais de atendimento psicossocial para a família que sofre violência doméstica e não apenas à vitima ou ao agressor; 2) é preciso que um trabalho permanente de sensibilização dos 
magistrados e promotores seja realizado para que as suas concepções culturais e familiares não venham a interferir negativamente nos processos e possíveis processos que venham a julgar. De fato, acredito que essa mudança apenas será possível com as futuras gerações de magistrados e promotores que terão histórias de vidas diferentes, em que o patriarcalismo familiar e estatal de até há poucos anos, não venha mais a influenciar os seus posicionamentos jurídico/sociais; 3) é necessário que a judicialização dos crimes de violência doméstica não seja a única forma de solucionar esses conflitos familiares. O problema da violência doméstica vai muito além do que a mera formalidade penal.

Ainda que os crimes de violência doméstica sejam tratados majoritariamente pelo Judiciário, é importante que atores e setores da sociedade possibilitem o acesso formal à Justiça às mulheres vítimas da violência doméstica. Possibilitar o acesso à Justiça vai muito além da simples inclusão do indivíduo no espaço jurídico. É propor formas alternativas de Justiça como: Justiça conciliatória, de composição de litígios ou, como denomina Cappelletti, uma Justiça coexistencial (Cappelletti; Garth, 2002). É também proporcionar ao cidadão o direito de compreender a importância de uma Justiça social e da cidadania plena e compreender o acesso à Justiça como "o acesso a uma determinada ordem de valores e diretos fundamentais para o ser humano” (Rodrigues apud Caovilla, 2003, p. 51).

\section{REFERÊNCIAS}

BEZERRA, Paulo Cesar Santos. Acesso à Justiça: um problema ético-social no plano da realização do direito. Rio de Janeiro: Renovar, 2001.

BRASIL. Conselho Nacional de Justiça. Lei Maria da Penha completa seis anos de vigência. In: Portal do CNJ. Disponível em: <http://www.cnj.jus.br/ noticias/cnj/20607-lei-maria-da-penha-completa-seis-anos-de-vigencia $>$. Acesso em: 19 fev. 2013. 
CAOVILLA, Maria Aparecida Lucca. Acesso à Justiça e cidadania. Chapecó: Argos, 2003.

CAPPELLETTI, Mauro; GARTH, Bryant. Acesso à Justiça. Porto Alegre: Sergio Antonio Fabris Editor, 2002.

DATASENADO. Violência doméstica e familiar contra a mulher: pesquisa de opinião pública nacional. 2011.

INSTITUTO AVON; IBOPE. Percepções sobre a violência doméstica contra a mulher no Brasil. 2009. Disponível em: <http://www.institutoavon.org.br/ mwg-internal/de5fs23hu73ds/progress?id=NnD7FP5EUf $>$. Acesso em: 6 mar. 2014.

MACHADO, Lia Zanotta. Violência doméstica contra as mulheres no Brasil: avanços e desafios ao seu combate. In Protegendo as mulheres da violência doméstica. FÓRUM NACIONAL DE EDUCAÇÃO EM DIREITOS HUMANOS. Brasília, 2006.

OBSERVATÓRIO BRASIL DA IGUALDADE DE GÊNERO. Participação das mulheres no Judiciário aumentou. Disponível em: <http://www.observatoriodegenero.gov.br/menu/noticias/participacao-das-mulheres-no-judiciario-aumentou/>. Acesso em: 5 fev. 2013a.

. Promotoras legais populares no combate à violência doméstica e familiar contra as mulheres. Disponível em: <http://www.observatoriodegenero.gov. $\mathrm{br} / \mathrm{menu} /$ noticias/promotoras-legais-populares-combate-a-violencia-domestica-e-familiar-contra-as-mulheres-entrevista-com-rubia-abs/>. Acesso em: 19 fev. 2013b.

CAOVILLA, Maria Aparecida Lucca. Acesso à Justiça e cidadania. Chapecó: Argos, 2003.

SANTOS, Boaventura de Sousa. Pela mão de Alice: o social e o político na pós-modernidade. 6. ed. São Paulo: Cortez, 1999.

. Para uma revolução democrática da Justiça. 2011. Disponível em: $<\mathrm{http}: / / 72.29 .69 .19 / \sim$ jal/images/stories/arquivos/RevDemJust_FEV2011. $\operatorname{pdf}>$. 
SILVA, Bárbara Garcia Ribeiro Soares da. A violência conjugal contra mulheres da classe média do município de São Paulo. 2007. Dissertação (Mestrado) Programa de Pós-Graduação em Sociologia da Universidade de São Paulo, São Paulo, 2007.

SOUSA, Jaime Luiz Cunha de; BRITO, Daniel Cunha de; BARP, Wilson José. Violência doméstica: reflexos das ordenações filipinas na cultura das relações conjugais no Brasil. In Teoria \& Pesquisa. Revista de Ciências Sociais, Ufscar, vol. 18, n. 1, jan./jun. 2009.

Recebido em: 10/4/2014

Aceito em: 5/12/2015 